\title{
Effect of exposure time and incubation period of various sterilants and antioxidants on the in vitro morphogenesis of guava explants
}

\author{
Roshan Zamir ${ }^{1}$ and Abdur- Rab ${ }^{2}$ \\ ${ }^{1}$ Principal Scientist, Nuclear Institute for Food \& Agriculture (NIFA), Peshawar-25120, Pakistan \\ ${ }^{2}$ Professor, Department of Horticulture, The University of Agriculture, Peshawar-25120, Pakistan
}

\begin{abstract}
This experiment was carried out to investigate the effects of various surface sterilants and antioxidants during in vitro propagation of guava (Psidium guajava L.). Different sterilants and exposure time significantly affected survival in shoot tip explants. Maximum survival response (43.3\%) was observed when shoot tips were exposed to $2 \% \mathrm{NaOCl}$ followed by $0.05 \% \mathrm{HgCl}_{2}$ and $4 \% \mathrm{CaOCl}$ with 36.7 and $33.3 \%$ survival respectively. Similarly 5 and 10 minutes exposure times were statistically at par with each other. The interaction between different sterilants and exposure time was non significant. As compared to soot tips explants, the effect of different sterilants on the survival of nodal explants was also significant. The highest survival response of $31.7 \%$ was shown by $0.05 \% \mathrm{HgCl}_{2}$ followed by $4 \% \mathrm{CaOCl}$ and $2 \% \mathrm{NaOCl}(29.2$ and $26.7 \%)$ respectively. Similarly the response of different exposure times (5 and 10 minutes) in case of nodal explants was non significant. Among all anti oxidants and incubation periods applied, dark incubation of cultures for 24 hours was effective which eliminated (34.3\%) browning followed by dip of explants in 75:50 $\mathrm{mg}^{-1}$ citric acid and ascorbic acid (31.8\%) while control was inferior to all and gave $11.7 \%$ browning elimination. Similarly the effect of antioxidants on type of explants (shoot tip and nodal explants) was also significant. The highest response of $37.8 \%$ was recorded in shoot tip explants while in nodal explants it was $14.5 \%$ only. The inter action between antioxidants and explants types was also significant. In over all, the highest browning elimination of 55\% was recorded in shoot tip explants when cultures were kept in dark for 24 hours. Whereas the most inferior results were shown by control treatments where only 6.7 and $16.7 \%$ browning was eliminated in tips and nodal explants.
\end{abstract}

Key words: Guava (Psidium guajava L.); Sterilants; Antioxidants; Survival response

\section{Introduction}

Guava (P. guajava L.) is one of the important fruit of family Myrtaceae. It is favorite fruit of both rich and poors in Indo-Pak subcontinent for its musky penetrating aroma, nutritional value, and affordable prices [1]. Guava is usually propagated by seeds and natural cross pollination up to $35 \%$ common in guava cultivars is responsible for the variability, low production, and inferior fruit quality in seedlings trees [1,2 and 3].

In vitro technique of plant propagation is an aseptic method by which small plant parts (plantlets) are aseptically cultured on artificial medium to initiate its growth by direct or indirect regeneration and multiplication [4]. It has a potential to increase the rate of producing planting materials [5 and 3]. However, the in vitro propagation of woody plants like guava is difficult due to phenolic exudations, fungal and bacterial contaminations [6, 3 and 7]. Contaminations due to microbial activities deteriorate cultures and as a result there is a little chance of shoot multiplication and rooting [4]. In vitro contamination is a serious problem which leads to severe production losses, low progeny performance and rejections of entire shipments of plants due to quarantine regulations [8]. For obtaining contamination free cultures the most important step is sterilization of explants. Various sterilization agents such as sodium hypochlorite, calcium hypochlorite, ethanol, mercuric chloride, hydrogen peroxide, silver nitrate and bromine water are being used in tissue culture to decontaminate the explants tissues [9]. These sterilants are also toxic to the plant tissues, hence best concentration and exposure time of sterilants to the explants is an essential step before culturing to achieve maximum survival rate. Therefore, in present experiment different surface sterilization reagents were used for 5-10 minutes to minimize the chances of contaminations in shoot tips and nodal explants of guava in vitro. Similarly, presence of phenolic compounds which causes death of explants is a serious problem in cultures in vitro [10]. In tissue culture phenolic compounds appears when the excised tissue after surface sterilization is cultured on the media which later on turns the media brown [11]. The problem of phenolic compounds exudation in culture medium is one of the limiting factor in propagation of many recalcitrant species especially guava [7 and 9].

Application of certain antioxidant compounds can help in the absorption of phenolics and are beneficial to reduce their adverse effects on the explants in the medium. Several protocols have been developed to minimize oxidation of phenolic compounds during in vitro culture but no one was perfected [7 and 9]. Different 
compounds such as polyvinylpolypyrrolidone (PVPP), solutions of citric acid and ascorbic acid and activated charcoals have been used as antioxidants for removing phenolics in guava explants in vitro but the success rate was very little [7, 9, 12, 13, 14 and 15]. Pre-incubation of explants on medium containing mineral salts treated with BAP $\left(200 \mathrm{mg} \mathrm{l}^{-1}\right)$ or PVPP, ascorbic acid , cystiene or citric acid was found to reduce formation of phenolic acids of explants [16].

Thus, it is possible to overcome this problem through the application of various antioxidants. These compounds were applied in apple [17] and mango [18]. However, browning of guava and walnut tissues was difficult to control [19]. Therefore, the present investigations were initiated which aimed to apply these selective substances to control contaminations and phenolic exudations from explants of field grown shoots and nodal segments of guava.

\section{Materials and methods}

This experiment was conducted in the Biotechnology Laboratory at Nuclear Institute for Food and Agriculture (NIFA), Peshawar (Pakistan) to investigate the effect of different surface sterilants and antioxidants on the aseptic in vitro culture of guava cv. Safeda shoot tips and nodal explants.

\section{Excising of explants and sterilization}

Plant material was collected from adult trees grown in the campus. Shoot pieces $4-5 \mathrm{~cm}$ long were taken from new flushes in April. After removing the unfolded leaves, the shoot pieces were cut into $1.0 \mathrm{~cm}$ pieces for preparing shoot tips while the nodal explants contained on node per explant. These were thoroughly washed under running tap water with one drop of Zip (detergent) for 30 minutes. The explants material was washed thrice with distilled water, followed by surface sterilization with $70 \%$ ethanol. The ethanol treated explants were further exposed to $\mathrm{HgCl}_{2}(0.05 \%), \mathrm{CaOCl}(4 \%), \mathrm{NaOCl}(2 \%)$ and $\mathrm{Ag} \mathrm{No}_{3}(0.2 \%)$ for 5-10 minutes with continuous shaking on orbital shaker. In another experiment to control tissue media browning, shoot tips and nodal explants were dipped in solution of citric acid $\left(75 \mathrm{mg} \mathrm{l}^{-1}\right)$ and ascorbic acid $\left(50 \mathrm{mg}^{-1}\right)$, cultured on MS medium containing $200 \mathrm{mg} \mathrm{l}^{-1}$ activated charcoal alone and in combination with Polyvenylpyrolidone (PVP) (Duchfa Int.) $100 \mathrm{mg} \mathrm{l}^{-1}$ and cultures were also incubated in the dark for 24 and 48 hours after culture.

\section{Medium preparation}

Murashige and Skoog medium [20] was used as a basic medium. The media was also added with $3.0 \%$ sucrose and solidified with $8 \mathrm{~g} \mathrm{l}^{-1}$ plant agar used for culturing the shoot tips. The $\mathrm{pH}$ of the medium was adjusted to 5.7 before autoclaving at $121 \mathrm{C}^{0}$ at $1.05 \mathrm{~kg} / \mathrm{cm}^{2}$ for 20 minutes.

\section{Culturing of explants and culturing conditions}

Shoot tips were cultured vertically in test tubes containing 15-20 ml medium while nodal explants were cultured in $500 \mathrm{ml}$ flasks containing 40-50 ml medium. The cultures were kept in growth chamber having $25 \pm 2$ $\mathrm{C}^{0}$ temperature and 12 hours photoperiod (4000 lux). One treatment of the cultures were kept in dark for 24 and 48 hours and then shifted to growth chamber.

\section{Data collection and experimental design}

The cultures were observed after two weeks for any bacterial or fungal contamination and media browning or phenolic exudations. The survived shoot tips and nodal explants were counted in each replication of all the treatments, averaged and converted into percent survival for contamination or browning with following formula;

$\%$ Survival (shoot tip/explants) $=$ Number of survived cultured (shoot tip or explants) $\times 100$

Total number of explants cultured

The experiments were carried out in a 2 factorial Completely Randomized Design and the treatments were replicated three times with twenty explants per culture. The data were statistically analyzed by using the software Stat. 8.1 USA analysis of variance and LSD test to check the level of significance between the treatments.

\section{Survival percentage of shoots tips}

\section{Results and discussions}

Different sterilants and exposure time had significantly affected survival in shoot tip explants (Table 1). The maximum survival response $(43.3 \%)$ was observed when shoot tips were exposed to $2 \% \mathrm{NaOCl}$ followed by $0.05 \% \mathrm{HgCl}_{2}$ and $4 \% \mathrm{CaOCl}$ with 36.7 and $33.3 \%$ survival respectively. The minimum survival (30\%) was recorded with $0.2 \% \mathrm{AgNO}_{3}$ (Table 1). Exposure times of 5 and 10 minutes had no significant affect on survival percentage in shoot tips of guava explants. However, higher survival (37.5\%) was recorded with 5 minutes exposure time as compared to $34.2 \%$ for 10 minutes (Table 1). The interaction between different sterilants and 
exposure time had no significant affect on survival of guava shoot tip explants. However, the maximum survival response $(48.3 \%$ ) was observed when shoot tips were exposed to $2 \% \mathrm{NaOCl}$ for 5 minutes followed by $38.3 \%$ with same treatment (Table 1).

During micropropagation, 3-15\% explants get contaminated which make micropropagation system less economical [21]. Sodium hypochlorite is an effective bactericide and is, therefore, widely used as disinfectant against microorganisms [22]. However, little is known about its mode of action. When dissolved in water, the hypochlorite salts leads to the formation of $\mathrm{HOCl}$, which is responsible for bactericidal activity [23]. It is common practice to apply surface sterilants to shoot tips to avoid contamination [4]. It is generally recommended that shoot tips are sterilized with calcium hypochlorite or with $10 \%$ commercial bleach for three minutes after soaking in a solution with a small amount of detergent e.g. Tween- 20 [24]. The superiority of $2 \%$ $\mathrm{NaOCl}$, irrespective of exposure time, as compared to other chemicals clearly indicates that it is an effective sterilant for cowpea, rice and sorghum seeds [25 and 22]. In an earlier experiment, Khattak et al. [7] reported that surface sterilization of guava shoot tip explants with $70 \%$ ethanol for one minute followed by treatment with $\mathrm{HgCl}_{2}, \mathrm{NaOCl}$ or ethanol for 5 minutes give better results while the concentration and exposure time are critical in survival percentage of shoot tips, no significant difference were observed in 5 or 10 minutes exposure time though exposure for 5 minutes were slightly superior. These observations suggests that 5 minutes exposure time may be the optimum exposure time to the surface sterilants used in the experiments [25]. Ramirez et al. [26] tested three concentrations of silver nitrate, mercuric chloride and sodium hypochlorite with three exposure times to reduce contaminations in adult guava nodal explants and suggested further disinfection with $70 \%$ ethanol for 1 minute followed by treatment with $2 \mathrm{~g} \mathrm{l}^{-1}$ benomyl and rafampicin at $100 \mathrm{mg} \mathrm{l}^{-1}$ after washing with running tap water for 16 hours. Shekafandeh and Khosh-Khui [9] also suggested use of different sterilants for in vitro establishment of guava explants and successfully controlled contaminations with mercuric chloride treatments.

In overall experiment, maximum survival response was given by $\mathrm{NaOCl}$ followed by $0.05 \% \mathrm{HgCl}_{2}$. The reason may be due to the effective detergent and bacteriocidal capability of $\mathrm{NaOCl}$ and $\mathrm{HgCl}_{2}$. $\mathrm{Non}$ Significant response (30-33.3\%) was observed when shoot tips explants were exposed to $\mathrm{AgNO}_{3}$ and $\mathrm{CaOCl}$ (Table 1). In overall, the best surface sterilization reagent for shoot tips explants was sodium hypochlorite followed by mercuric chloride, calcium hypochlorite and silver nitrate.

\section{Survival percentage of nodal explants}

The data in table 2 reveals that different sterilants significantly affected the survival percentage of nodal explants in guava. The highest survival response of $31.7 \%$ was recorded with $0.05 \% \mathrm{HgCl}_{2}$ followed by $4 \% \mathrm{CaOCl}$ and $2 \% \mathrm{NaOCl}$ with 29.2 and $26.7 \%$ respectively. The minimum survival percentage of nodal explants $(22.2 \%)$ was recorded with $0.2 \% \mathrm{AgNO}_{3}$. While $4 \% \mathrm{CaOCl}$ and $2 \% \mathrm{NaOCl}$ were statistically at par with each other. The effect of different exposure times (5 and 10 minutes) on nodal explants was non significant. The survival response $(29.8 \%)$ was higher with 10 minutes exposure time as compared to 5 minutes $(25 \%)$. The interaction between different sterilants and exposure time was also non significant (Table 2). However, the most effective sterilant was $\mathrm{HgCl}_{2}$ for 10 minutes with survival of $41.6 \%$ nodal explants followed with $31.7 \%$ by $4 \% \mathrm{CaOCl}$ for 5 minutes.

For obtaining contamination free cultures the most important step is sterilization of explants. Due to hardy nature of nodal explants as compared to the shoot tips, the survival percentage was also lower as compared to shoot tips. Lower survival percentage of nodal explants in this study is because of greater contaminations in nodal explants cultures. This may be the reason that the survival of explants decreasing with increase in age of explants. The morphogenetic growth pattern of the cell changes according to the physiological age of the plant material, resulting in direct correlation between the sensitivity of the tissues to the sterilants and the age of explants [27 and 28]. The younger explants (shoot tips) consists of delicate tissues and hence required lesser time for surface sterilization than nodal explants where 10 minutes exposure time has shown best results [28]. The incidence of bacterial and fungal contamination was higher in explants taken from the nodal region than in those taken from the stem internodes as the bacteria may be associated with hairs present at the nodes [29].

The superiority of mercuric chloride over other sterilants has also been reported by Ahmad et al. [30], while carrying out surface sterilization of Piper nigrum L. and recorded elimination of $75 \%$ contaminations during in vitro. The findings of our study and effectiveness of mercuric chloride is also supported by the earlier experiments of Mishra et al. [14] and Khattak et al. [7] and got best aseptic cultures as well as higher survival with pretreatment of explants with mercuric chloride $(0.1 \%)$ for 5 minutes and sodium hypochloride $(1 \%)$ for 8 minutes and further treating explants with Twin-20 and then kept under running tap water for 1 hour followed by 4-5 washing with autoclaved distilled water.

Oyebanji et al. [22] also recommended surface sterilization of cowpea, rice and sorghum seeds with sodium hypochlorite irrespective of exposure time because of cost effectiveness, readily availability and can be diluted in proper concentrations to eradicate bacterial and fungal contaminations. 
Badoni and Chauhan [25] also carried out surface sterilization with different concentration and exposure time of $\mathrm{NaOCl}$ and $\mathrm{HgCl}_{2}$ in Solanum tubersum L. However, they found that sodium hypochlorite dip for 8 minute was suitable sterilization agent after 5 minute of savlon wash, 30-second dip in ethanol and finally washed with double distilled water. The reason for the superiority of $\mathrm{NaOCl}$ in their study may be due the annual herbaceous nature of Solanum tubersum which do not easily allow penetration of microbes due to higher cell division as compared to the woody perennial plants like guava. However, in our studies $\mathrm{NaOCl}, \mathrm{HgCl}_{2}$ and silver nitrate for 5 minutes was not so effective ( $25 \%$ and $22 \%$ survival only). It may be due to hardy nature of guava and due to the presence of indigenous contaminations in woody plants [3 and 6]. The second most survival response in our studies was recorded with $4 \%$ calcium hypochlorite $(29.2 \%)$. This concur the findings of our study; where in effectiveness of calcium hypochlorite is also recommended by Roca et al. [31] while treating potatoes explants with $0.25 \%$ calcium hypochlorite for 5 minutes. In present studies, $\mathrm{HgCl}_{2}$ and calcium hypochlorite has turned out to be better sterilants than sodium hypochlorite and silver nitrate due to better sterilization and bleaching effects and hence extensively used for various explants sterilization. Miller and Lipschutz [32] successfully surface sterilized the excised shoot tips of potatoes in $1 \%$ sodium hypochlorite solution containing $0.1 \%$ Tween-20 for 7 minutes.

\section{Survival response of shoot tips and nodal explants to browning}

The data regarding survival response of shoot tips and nodal explants to various antioxidants against browning presented in table 3 shows that all antioxidants decreased browning of shoot tips and nodal explants significantly. Among all anti oxidants, dark incubation of cultures for 24 hours was effective which gave $34.38 \%$ browning free explants, followed by $75: 50 \mathrm{mg} \mathrm{l}^{-1}$ citric acid and ascorbic acid (31.8\%), while control was inferior to all where survival rate was only $11.7 \%$. Similarly $200 \mathrm{mg} \mathrm{l}^{-1}$ Charcoal alone eliminated $29.3 \%$ browning as compared to its interaction with $100 \mathrm{mg} \mathrm{l}^{-1}$ Poly vinyl pyrolidone (PVP) (17.7\%) only (Table 3). Dark incubation of shoot tips and nodal explants for 24 hours gave $34.3 \%$ survival as compared to 48 hours where $27.7 \%$ survival was recorded. Combination of both PVP and activated charcoal increased browning and reduced success to $17.7 \%$ only (Table 3 ). Similarly the effect of antioxidants on explant types (shoot tip and nodal explants) was also significant. The highest survival response of $37.8 \%$ was recorded in shoot tip explants while in nodal explants it was only $14.5 \%$. The interaction between antioxidants and explants types was also significant. The highest survival of 55\% was recorded in shoot tip explants when cultures were kept in dark for 24 hours. It was followed by 50\% survival when shoot tips were dipped in solution of 75:50 $\mathrm{mg}^{-1}$ citric and ascorbic acid. The most inferior results were shown by control treatments in shoot tips (16.7\%) and in nodal explants $(6.7 \%)$. As compared to shoot tip explants, the lowest survival response was shown by nodal explants. However, in case of nodal explants the highest survival response (23.8\%) was shown by 48 hours dark incubation.

The presence of phenolic compounds in plant tissues is a serious problem to in vitro culture establishment which sometimes causes death of explants [10]. Tissue blackening occurs due to action of coppercontaining oxidase enzymes (polyphenoloxidases like tyrosinases) which are released or synthesized in oxidative conditions after tissue wounding [33 and 34]. The in vitro establishment of guava in tissue culture is very difficult [19]. The cut surfaces of the explants get brown by releasing browning material into the medium which ultimately inhibits its morphogenetic activity. Fitchet [35] studied Dimple guava by dipping shoot tip explants in antioxidant solution (75:50 $\mathrm{mg} \mathrm{l}^{-1}$ citric and ascorbic acid) and reported that application of antioxidants was useful in preventing oxidative browning. However, in our studies, the explants were cultured immediately after dipping in antioxidant solutions. Furthermore, 24 hours incubation period resulted in the maximum elimination of browning followed by citric acid and ascorbic acid. The reason of superiority with dark incubation may be that light act as a catalyst in phenolic exudation and browning. These results are strongly supported by the earlier studies carried out by Mishra et al. [14], who supplemented $500 \mathrm{mg}$ citric acid in the MS media and incubated the cultures initially in complete dark for 24 hours to reduce phenolic browning of media and explants. In another experiment, Amin and Jaiswal [12 and 13] also recommended the pretreatment of explants with antioxidant solutions $\left(75 \mathrm{mg} \mathrm{l}^{-1}\right.$ citric acid and $50 \mathrm{mg} \mathrm{l}^{-1}$ ascorbic acid) after surface sterilization of explants for controlling phenolic exudations and establishment of cultures.

Tang et al. [36] studied PVP and dTT for controlling in vitro browning. They reported that such antioxidant increases shooting and rooting up to $19 \%$ in Pinus virginiana Mill. Many medium components have been observed to decrease or eliminate tissue browning such as inclusion of nitrate as a source of nitrogen; increased concentration of phytagel or using gelrite instead of agar [16]. Many authors have also tested phenol traps such as activated charcoal; adsorbent resin; citric acid; cysteine; PVPP; and antioxidants such as ascorbic acid or glutathione (GSH) for minimization of browning [16]. By contrast, Lindfors et al. [37] reported that onset of tissue browning has been associated with changes in protein pattern, amino acid content, ethylene production and the occurrence of saccharose and accumulation of starch etc that eventually lead to growth inhibition or death of explants. In addition, other types of phenolic exudates appear at the end of incubation period and are apparently products of dying cells [11]. 
In present studies, nodal explants were more susceptible to browning than shoot tips explants. The reason may be that shoot tips are younger than nodal explants and release little or no phenolics in the medium [28]. Phenolic exudation from nodal explants was successfully controlled by agitating the solution containing antioxidants ascorbic acid and citric acids each with concentration of $100 \mathrm{mg} \mathrm{l}^{-1}$ [9]. Present studies are in the line with the findings of Gasman et al. [19], who reported that complete removal of browning in guava and walnut in vitro culture was not possible by the application of various antioxidants. During our experiment, however, it was observed that dark incubation of culture for 24 hours were somewhat effective in controlling browning of shoot tips as compared to nodal explants. It was noticed that browning of the material was more intense in case of nodal explants. It could be that the nodal explants contained more phenolic compounds as compared to shoot tips. Only the combination of citric acid and ascorbic acid was effective in the case of shoot tips explants but have lower potential when the selected explants were nodal. Combination of PVP and activated charcoal, however, exhibited manimum role in controlling browning in shoot tips and nodal explants. Significantly higher response was observed when both the tissues were exposed to dark incubation for different time intervals (Table 3).

\section{References}

[1]. R. Zamir, G. S. S. Khattak, T. Mohammad, S. A. Shah, A. J. Khan, N. Ali, In vitro mutagenesis in guava (Psidium guajava L.). Pakistan Journal of Botany, 35, 2003, 825-828.

[2]. C. M. Menzel, Guava: An exotic fruit with potential in Queensland. Queensland Agriculture Journal, 111, 1985, 93-98

[3]. M. K. Rai, P. Asthana, V. S. Jaiswal, U. Jaiswal, Biotechnological advances in guava (Psidium guajava L.): Recent developments and prospects for future research. Trees, 24, 2010, 1-12.

[4]. E. F. George, Plant propagation by tissue culture: Part $1 \& 2$. The technology, $2^{\text {nd }}$ Edn. Exegenetics, Edington, UK, 1993, pp, 337356.

[5]. S.T. Shah, R. Zamir, J. Ahmad, G. Lutfullah, In vitro regeneration of plantlets from seedlings explants of guava (Psidium guajava L.) Cv. Safeda. Pakistan Journal of Botany, 40, 2008, 1195-1200.

[6]. H. Krishna, S. K. Singh, Biotechnological advances in mango (Mangifera indica L.) and their future implication in crop improvement a review. Biotechology Advances, 25, 2007, 223-243.

[7]. M. S. Khattak, M. N. Malik, M. A. Khan, Effects of surface sterilization agents on in vitro culture of guava (Psidium guajava L.) Cv. Sufeda tissue. Sarhad Journal of Agriculture Research, 6, 1990, 151-154.

[8]. A. C. Cassells, Problems in tissue culture: Culture contamination. In: Micropropagation. Technology and Application. (Eds. Debergh P. C. and Zimmerman R. H.) Kluwer Academic Publishers, Dordrecht, 1991, 31-44.

[9]. A. Shekafandeh, M. Khosh-Khui, Factors affecting in vitro establishment of guava (Psidium guava L.) explants. American-Eurasian Journal of Agriculture \& Environmental Sciences, 2, 2007, 672-679.

[10]. M. E. Compton, J. E. Preece, Exudation and explant establishment. Intl. Asso.. Intl. Asso. Plant Tissue Cult., Newsletter, 50, 1986, 9-18

[11]. P. Seneviratne, G. A. S. Wijesekara, The problem of phenolic exudates in in vitro cultures of mature Hevea brasiliensis. Journal of Plantation Crops, 24, 1996, 54-62.

[12]. M. N. Amin, V. S. Jaiswal, Rapid clonal propagation of guava through in vitro shoot proliferation on nodal explants of mature trees. Plant Cell, Tissue and Organ Culture, 9, 1987, 235-243

[13]. M. N. Amin, V. S. Jaiswal, Micropropagation as an aid to rapid cloning of a guava cultivar. Scientia Horticulturae, 36, 1988, 89-95

[14]. D. S. Mishra, J. P. Tiwari, S. Lal, In vitro cloning of guava (Psidium guajava L.) cv. Pant Prabahat. In: Abstract of 1st international guava symposium, CISH, Lucknow, India, 2005, 32-33.

[15]. R. Chandra, M. Mishra, A. Bajpai, Biotechnological interventions for improvement of guava (Psidum guajava L.). Proceeding of $1^{\text {st }}$ international guava symposium, CISH, Lucknow, India, 2005, pp, 19-25

[16]. M. K. Keskitalo, Exploring biodiversity to enhance bioactivity in the genus Tanacetum through protoplast fusion. Thesis, University of Helsinki. Finland, 1999.

[17]. O. P. Jones, C. A. Pontikis, M. E. Hopgood, In vitro propagation of the five apple scion cultivars. Journal of Horticulture Sciences, 54, 1979, 155-158.

[18]. R. E. Litz, R. L. Knight, S. Gazit, Somatic embryos from cultured ovules of polyembryonic Manifera indica L. Plant Cell Reports, 1, 1982, 264-266.

[19]. K. G. Gassman, M. O. Mapes, R. M. Bullock, Synergistic effects of guava (Psidium guajava_L.) B-30 stem exudue with auxin. Plant propagator. Horticulturae, 49, 1978, 3862-1979

[20]. T Murashige, F. A. Skoog, Revised medium for rapid growth and bioassays with tobacco tissue cultures. Physiology Plantarum, 15, 1962, 473-497.

[21]. C. C. Leifert, Morris, W.M. Waites, Ecology of microbial saprophytes and Pathogens in field grown and tissue cultured plants. CRC Critical reviews plant science, 13, 1994, 139-183

[22]. O. B. Oyebanji, O. Odebunmi, N. B. Gladima, M. S. Idris, Simple, effective and economical explant-surface sterilization protocol for cowpea, rice and sorghum seeds. African Journal of Biotechnology 8, 2009, 5395-5399.

[23]. S. Nakagarwara, T. Goto, M. Nara, K. Ozava-Hoota, Y. Arata, Spectroscopic characterization and pH dependence of bacterial activities of aqueous chlorine solution. Analls of Science, 14, 1998, 691-698.

[24]. Q. C. Wang, H. R. Tang, Q. Quan, G. R. Zhou, Phenol induced browning and establishment of shoot-tip explants of .Fuji.apple and Jinhua. pear cultured in vitro. Journal of Horticultural Science, 69, 1994, 833-839.

[25]. A. Badoni, J. S. Chauhan, In vitro sterilization protocol for micropropagation of Solanum tuberosum cv. Kufri Himalini’ Academia Arena, 2, 2010, 1-4.

[26]. V. Ramírez, M. S. Leon-de-Sierralta, A. Urdaneta-Fernandez, Evaluaion of surface disinfectants on the in vitro establishmen of guava (Psidium guajava L.) and Psidium friedrichsthaliamum (Berg) Nierdz. Revista -de-Faculad-de-Agronomia, Universidad-deZulia, 16, 1999, 243-255.

[27]. P. Papadatou, C. Pontikis, E. Ephtimiadou, M. Lydaki, Rapid multiplication of guava seedlings by in vitro shoot culture. Scientia Horticulturae, 45, 1990, 99-103.

[28]. C. S. Loh, A. N. Rao, Clonal propagation of guava (Psidium guajava L.) from seedling and grafted plants and adventitious shoot formation in vitro. Scientia Horticulturae, 39, 1989, 31-39. 
Effect of exposure time and incubation period of various sterilants and antioxidants on the in .....

[29]. P. J. Mathias, P. G. Alderson, R.R.B. Leakey, Bacterial contamination in tropical hardwood cultures. Acta Horticulture, 212, 1987, 43-4

[30]. N. Ahmad, H. Fazal, B. H. Abbasi, M. Rashid, T. Mahmood, N. Fatima, Efficient regeneration and antioxidant potential in regenerated-tissues of Piper nigrum L. Plant Cell, Tissue and Organ Culture, 102, 2010, 129-134.

[31]. W. M. Roca, N. O. Espinoza, M. R. Roca, J. E. Bryan, A tissue culture method for the rapid propagation of potatoes. Int. potato center (CIP). Kluwer Academic publishers London, 1978, pp. 15-17

[32]. S. A. Miller, L. Lipschutz, Potato in: Ammirato P.V., Evans, D., Sharp W. R. and Yamada Yasuguki (eds.), Handbook of plant tissue culture, New York. McMillan publishing company, 3, 1984, 291-293

[33]. A. Scalbert, B. Monties, J. M. Favre, Polyphenols of Quercus robur adult tree and in vitro grown calli and shoots. Phytochemistry, 27, 1988, 3483-3488.

[34]. T. R. Marks, S. E. Simpson, Reduced phenolic oxidation at culture initiation in vitro following the exposure of field-grown stock plants to darkness or low levels of irradiance. Journal of Horticulture Sciences, 65, 1990, 103-111.

[35]. PM Fitchet, Dimple guava established in tissue culture. Inligtings bulletin-Navorsing sinstituut- vir-Sitrus -en-Subtropiese-Vrugte. Horticulturae, 212, 1990

[36]. W. Tang, L. C. Harris, V. Outhavong, R. J. Newton, Antioxidants enhance in vitro plant regeneration by inhibiting the accumulation of peroxidase in Virginia pine (Pinus virginiana Mill.). Plant Cell Reports, 22, 2004, 871-877.

[37]. A. Lindfors, H. Kuusela, A. Hohtola S. Kupila-Ahvenniemi, Molecular correlation of tissue browning and deterioration in Scots pine calli. Biologia Plantarum, 32, 1990, 171-180.

Table 1: Effect of sterilants on survival percent of guava shoot tips

\begin{tabular}{l|c|c|c}
\hline \multirow{2}{*}{ Sterilants } & \multicolumn{2}{|c|}{ Exposure time } & \multirow{2}{*}{ Means } \\
\cline { 2 - 3 } & $5 \mathrm{~min}$ & $10 \mathrm{~min}$ & \\
\hline $2 \% \mathrm{NaOCl}$ & 48.3 & 38.3 & $43.3 \mathrm{a}$ \\
$0.05 \% \mathrm{HgCl}$ & 38.3 & 35.0 & $36.7 \mathrm{~b}$ \\
$4 \% \mathrm{CaOCl}$ & 33.3 & 33.3 & $33.3 \mathrm{bc}$ \\
$0.2 \% \mathrm{AgNO}_{3}$ & 30.0 & 30.0 & $30.0 \mathrm{~cd}$ \\
\hline Means & 34.2 &
\end{tabular}

LSD value $=2.12$

Means with same letters are not significantly different at $\mathrm{P} \leq 0.05$ using LSD test.

Table 2: Effect of sterilants on survival percent of guava nodal explants

\begin{tabular}{l|lc|l}
\hline \multirow{2}{*}{ Sterilant/strength } & \multicolumn{2}{|c|}{ Exposure time } & Means \\
\cline { 2 - 3 } & $5 \mathrm{~min}$ & $10 \mathrm{~min}$ & \\
\hline $2 \% \mathrm{NaOCl}$ & 25.0 & 28.3 & $26.7 \mathrm{c}$ \\
$0.05 \% \mathrm{HgCl}$ & & 41.7 & $31.7 \mathrm{a}$ \\
$4 \% \mathrm{CaOCl}$ & 21.7 & 26.7 & $29.2 \mathrm{~b}$ \\
$0.2 \% \mathrm{AgNO}_{3}$ & 31.7 & 22.7 & $22.2 \mathrm{~d}$ \\
\hline Means & 21.7 & & \\
\hline
\end{tabular}

LSD value for means $=1.2$

Means with same letters are not significantly different at $\mathrm{P} \leq 0.05$ using LSD test

Table 3: Survival response of guava shoot tips and nodal explants to various antioxidants and incubation period during in vitro culture

\begin{tabular}{l|cc|l}
\hline Antioxidants and incubation period & Shoot tips & Nodal explants & Means \\
\hline Dip in C. acid and A. acid solution (75:50) $\mathrm{mg} \mathrm{l}^{-1}$ & $50.0 \mathrm{~b}$ & $13.7 \mathrm{j}$ & $31.8 \mathrm{~b}$ \\
Addition of 100 $\mathrm{mg} \mathrm{l}^{-1}$ PVP to medium & $40.0 \mathrm{~d}$ & $21.7 \mathrm{~h}$ & $30.8 \mathrm{c}$ \\
Addition of PVP + activated charcoal to medium & $26.7 \mathrm{f}$ & $8.7 \mathrm{k}$ & $17.7 \mathrm{~F}$ \\
48 hours dark incubation of cultures & $31.7 \mathrm{e}$ & $23.7 \mathrm{~g}$ & $27.7 \mathrm{e}$ \\
24 hours dark incubation of cultures & $55.0 \mathrm{a}$ & $13.7 \mathrm{j}$ & $34.3 \mathrm{a}$ \\
Addition of Activated Charcoal 200 $\mathrm{mg} \mathrm{l}^{-1}$ & $45.0 \mathrm{c}$ & $13.7 \mathrm{j}$ & $29.3 \mathrm{~d}$ \\
Control & $16.7 \mathrm{i}$ & $6.7 \mathrm{l}$ & $11.7 \mathrm{~g}$ \\
\hline Means & $37.8 \mathrm{a}$ & $14.5 \mathrm{~b}$ & \\
\hline
\end{tabular}

LSD at $\mathrm{P} \leq 0.05=1.31$

Means with same letters are not significantly different using LSD test 